\title{
PATEN DALAM SISI PRODUK TWITTER
}

\section{Putra Rahmadi \\ 155100058}

Fakultas Komputer, 4487571-67

putrarahmadi.student@umitra.ac.id

\begin{abstract}
Twitter telah mendapatkan popularitas di seluruh dunia dan saat ini memiliki lebih dari 100 juta pengguna. Hal ini kadang-kadang digambarkan sebagai "SMS dari internet". Twitter memiliki logo yang di paten kan berupa seekor burung berwarna biru yang bernama "Larry the "Bird", dinamai setelah nama seorang mantan pemain basket $\underline{\text { NBA, }}$ Larry Bird.
\end{abstract}

Kata Kunci : paten pada logo twitter

\section{A. INTRODUCTION}

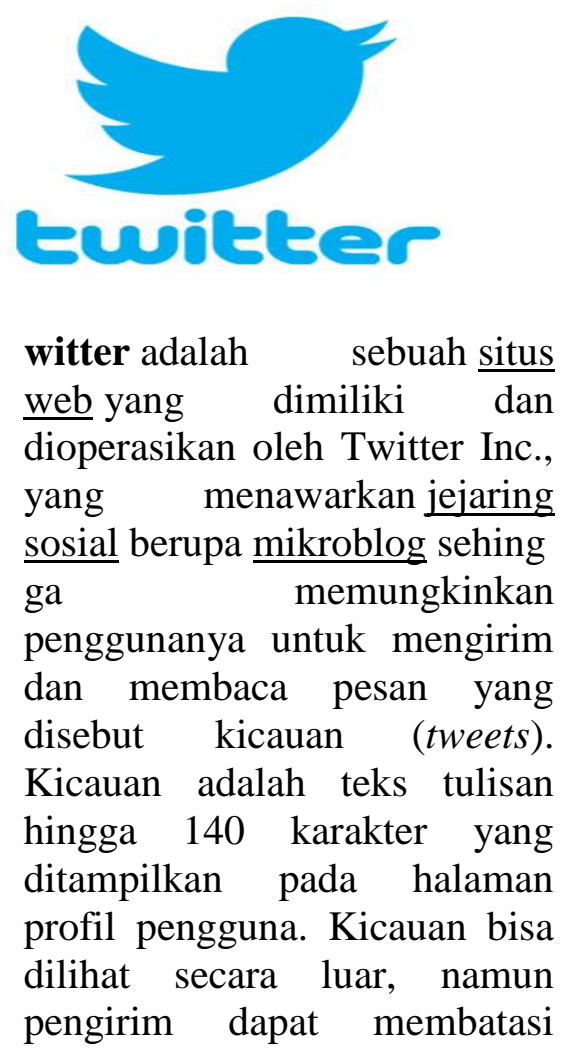

pengiriman pesan ke daftar teman-teman mereka saja. Pengguna dapat melihat kicauan penulis lain yang dikenal dengan sebutan pengikut ("follower").

Twitter sendiri berawal dari sebuah diskusi yang diselenggarakan oleh anggota dewan dari Podcasting perusahaan Odeo. Dalam pertemuan tersebut, Jack Dorsey memperkenalkan ide twitter dimana individu bisa menggunakan SMS layanan untuk berkomunikasi dengan sebuah kelompok kecil. Proyek ini dimulai pada tanggal 21 secara terbuka pada tanggal 15 Juli 2006. Twitter menjadi perusahaan sendiri pada bulan April 2007. Popularitas Twitter mulai 
meningkat pada tahun 2007 ketika terdapat festival South by Southwest (SXSW). Selama acara tersebut berlangsung, penggunaan Twitter meningkat dari 20.000 kicauan per hari menjadi 60.000. Reaksi di festival itu sangat positif. Pada tanggal 14 September 2010, Twitter mengganti logo dan meluncurkan desain baru dan logo berubah lagi menjadi "Larry the "Bird" pada tanggal 5 Juni 2012. Logo tersebutpun langsung di paten kan agar tidak ada dari perusahaan lain meniru atau mengcopy logo burung biru tersebut.

\section{B. CONCLUSION}

witter adalah situs web yang dioperasikan oleh Twitter Inc, twitter pertama kali di podcasting oleh perusahaan odeo. Dan kini twitter telah keluar dari perusahaan odeo dan kini twitter memiki perusahaan sendiri. Twitter diartikan sebagai kicauan, Kicauan diartikan sebagai teks tulisan hingga 140 karakter yang ditampilkan pada halaman profil penggunanya. Dan twitter berganti logo menjadi burung biru yang di paten kan untuk menjadi logo twitternya

\section{ACKNOWLEDGEMENT}

University Of Indonesia

University Of Mitra Indonesia

Telkom University

University Of Mellbourne

Saitama University 
"Sistem Informasi Monitoring Inventori Barang Pada Balai Riset Standardisasi Industri Bandar Lampung," J. Inform., Vol. 13, No. 1, Pp. 90-98, 2014.

[4] Putra, Arie Setya. "2018 Artikel Struktur Data, Audit Dan Jaringan Komputer." (2018).

[5] Putra, A. S. (2018, July 17). Paperplain Fundamental Create Application With Borland Delphi 7.0 University Of Mitra Indonesia. Retrieved From Osf.Io/Pbrn9.

\section{REFERENCE (Based ISO 690 )}

[1]

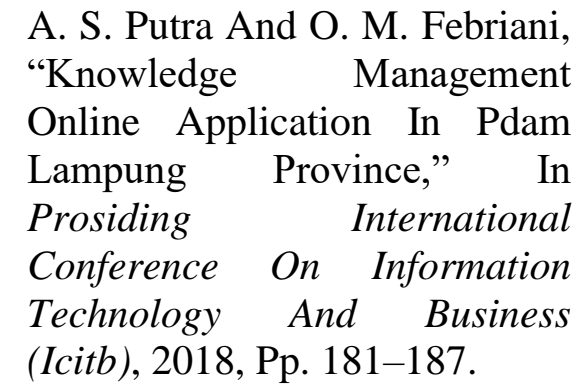

[2] A. S. Putra, O. M. Febriani, And B. Bachry, "Implementasi Genetic Fuzzy System Untuk Mengidentifikasi Hasil Curian Kendaraan Bermotor Di Polda Lampung," J. Sist. Inf. Dan Manaj. Basis Data, Vol. 1, No. 1, Pp. 21-30, 2018.

[3] O. M. Febriani And A. S. Putra,

\section{E. REFERENCE(Based APA )}

Putra, A. S., Aryanti, D. R., \& Hartati, I. (2018, November). Metode SAW (Simple Additive Weighting) sebagai Sistem Pendukung Keputusan Guru Berprestasi (Studi Kasus: SMK Global Surya). In Prosiding Seminar Nasional Darmajaya (Vol. 1, No. 1, pp. 85-97).

Sari, D. P., Febriani, O. M., \& Putra, A. S. (2018, November). Perancangan Sistem Informasi SDM Berprestasi pada SD Global Surya. In Prosiding Seminar Nasional Darmajaya (Vol. 1, No. 1, pp. 289-294).

Putra, A. S. (2018). Paperplain: Execution Fundamental Create Application With Borland Delphi 7.0 University Of Mitra Indonesia. 
Putra, A. S., Sukri, H., \& Zuhri, K. Sistem Monitoring Realtime Jaringan Irigasi Desa (JIDES) Dengan Konsep Jaringan Sensor Nirkabel. IJEIS (Indonesian Journal of Electronics and Instrumentation Systems), 8(2), 221232.

Darmawan, A., Yuliawati, D., Marcella, O., \& Firmandala, R. (2016). Sistem Absensi dan Pelaporan Berbasis Fingerprint dan SMS Gateway. EXPLORE, 7(1).

Febriani, O. M., Wahyuni, T., \& Yusuf, S. (2017). DESIGN OF WEBSITE-BASED INFORMATION SYSTEM FOR EDOCUMENT ADMINISTRASI IN THE COMMUNITY SERVICE UNIT (A Case Study at Rajabasa District). INTERNATIONAL JOURNAL OF COMPUTERS \& TECHNOLOGY, 16(7), 7010-7020.

Febriani, O. M., \& Wahyuni, T. (2017, October). PERANCANGAN SISTEM E-DOCUMENT ADMINISTRASI LOGBOOK PENELITIAN PADA UNIT LAYANAN DI BANDAR LAMPUNG. In Prosiding Seminar Nasional Darmajaya (Vol. 1, No. 1, pp. 187-194).

Febriani, O. M., \& Permadi, A. B. (2017). Implementasi Sistem Aplikasi Data Bimbingan dan Pelanggaran Siswa pada Sekolah Menengah Atas di Lampung Tengah dengan Metode Analisis dan Desain Sistem Terdistribusi (SSAD). EXPERT, 7(1).
Febriani, O. M., \& Ambarwati, L. (2015). PERANCANGAN APLIKASI PENGOLAHAN DATA PENJUALAN UKM KELANTING KHAS TELO DESA SIDOHARJO KECAMATAN JATI AGUNG KABUPATEN LAMPUNG SELATAN. Jurnal Teknologi Informasi dan Bisnis Pengabdian Masyarakat Darmajaya, 1(1), 77-95.

Febriani, O. M. (2015). Rancang Bangun Aplikasi Ecommercemenggunakan Freewebstore pada UKM Kelanting di Desa Sidoharjo Lampung Selatan. Prosiding Sembistek 2014, 1(02), 446-458. 